Detecting, Locating, and Characterizing Remote Power Sources

Philip Harben, Charles Carrigan, Barry Kirkendall, David Simons

February 14, 2005 
This document was prepared as an account of work sponsored by an agency of the United States Government. Neither the United States Government nor the University of California nor any of their employees, makes any warranty, express or implied, or assumes any legal liability or responsibility for the accuracy, completeness, or usefulness of any information, apparatus, product, or process disclosed, or represents that its use would not infringe privately owned rights. Reference herein to any specific commercial product, process, or service by trade name, trademark, manufacturer, or otherwise, does not necessarily constitute or imply its endorsement, recommendation, or favoring by the United States Government or the University of California. The views and opinions of authors expressed herein do not necessarily state or reflect those of the United States Government or the University of California, and shall not be used for advertising or product endorsement purposes.

This work was performed under the auspices of the U.S. Department of Energy by University of California, Lawrence Livermore National Laboratory under Contract W-7405-Eng-48. 


\section{Detecting, Locating, and Characterizing Remote $\underline{\text { Power Sources }}$}

(Final Report for FY04 LDRD Feasibility Study, Tracking Code 04-FS-017)

P. E. Harben, C.R. Carrigan, B.A. Kirkendall, D.J. Simons 


\begin{abstract}
A feasibility study to determine range and back-azimuth detection methods for an isolated generator powering common loads was completed. The study deployed 3component $\mathrm{E}$ and $\mathrm{B}$ field sensors with sampling rates of $100 \mathrm{kHz}$ in a low noise test location in Southern California. Scripted power and load cycling was recorded at ranges of 40 meters to $4 \mathrm{~km}$ from the generator/load source. Three loads were tested: a 100 meter string of lights, an inverter powering an air blower, and a resistive heater. No Efield or B-field radiated signals were detected at ranges greater than 40 meters with a signal-to-noise ratio greater than one. Large variations in the broadband background electromagnetic noise were observed and may have been responsible for null detections at some measurement locations. At the 40-meter station, a frequency shift upon generator loading was observed for all load types. Harmonics from the detuned generator (operating at $56.7 \mathrm{~Hz}$ ) could be observed for all load types but were most pronounced for the inverter source. A back-azimuth estimation methodology was applied to detected harmonics with stable and consistent results. For the inverter source, consistent back azimuths to the source were determined for the fundamental and higher detected harmonics up to the $31^{\text {st }}$. The method was applied to narrow band "noise" at $60 \mathrm{~Hz}$ and produced bimodal directions that roughly pointed to large population centers. Details of the method are withheld in this report pending a record of invention submittal. Although the generator/load combinations, which utilized wiring that tended to minimize stray signals, cannot yet be detected at large stand-off range without application of noisefiltering methods, the back-azimuth method appears promising and should be applied to other source types and frequency ranges where an E and B field can be detected. A record of invention describing this new back-azimuth method has been submitted to the Intellectual Property Law Group.
\end{abstract}




\section{INTRODUCTION}

All electric power systems seek to minimize transmission loss. One form of loss that is virtually impossible to eliminate is the radiated field loss that comes with changing loads in a power generation and utilization system. This is energy loss due to a radiated electromagnetic field that is highly dependent on the specifics of the generator and loads and the result of an imbalanced system. An isolated and remote power source such as a generator will always produce an electromagnetic field that can be detected at some stand-off range. The range, however, will be strongly dependent on the power utilization purpose and the specific layout of the generator and loads. Detection of signals at the low frequency of $60 \mathrm{~Hz}$ (and higher harmonics) are well within the complex electromagnetic near-field region for stand-off ranges less than $1000 \mathrm{~km}$. High sensitivity three-axis Efield measurements, along with corresponding B-field measurements allowed for the development of a method to calculate a back-azimuth to the source. This may allow for a determination of the location of a source within the near-field regime and thereby hold promise for source location capability at low frequency based on point vector $\mathrm{E}$ and $\mathrm{B}$ field measurements.

This feasibility study explores the possibilities for stand-off detection and location of a generator source powering realistic loads in the field through point vector E and B field measurements. The core effort was the design and execution of a field experiment that collected broadband and high dynamic range $\mathrm{E}$ and $\mathrm{B}$ field data from a number of source and sensor configurations and locations. The goal was to analyze these data to determine the limitations of detection and location and explore the application space that may prove fruitful in follow-on studies.

Assessing the capability of B and E field measurements to detect and locate an isolated source of power prompted this study, however, the data collected and the techniques assessed are beyond this narrow scope. High dynamic range E and B field data was collected in a $0-50 \mathrm{kHz}$ bandwidth, allowing for an assessment of background noise and signal analysis over a much larger bandwidth than that needed for power frequency analysis (60-3000 Hz). The data collected enabled an evaluation of the of a back-azimuth analysis methodology at a large range of frequencies on signals and on background noise. 


\section{FIELD DATA COLLECTION}

The Carrizo Plain National Monument in Southern California was chosen as the field site (see Figure 1). The site is remote and has a low background electromagnetic noise environment. Site use permission was obtained through the Bureau of Land Management.

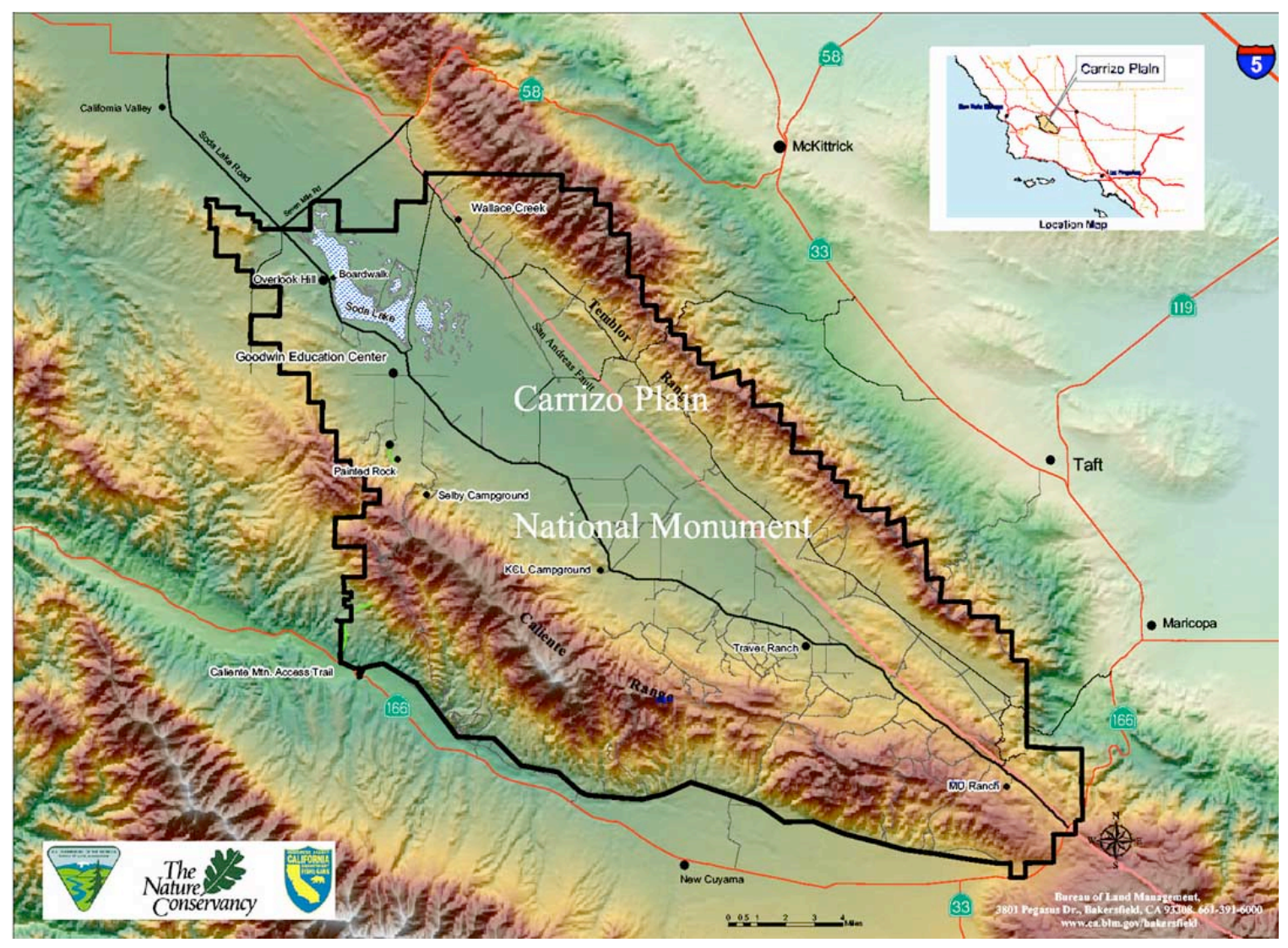

\section{Figure 1) The Carrizo Plain National Monument in Southern California was a suitable low electromagnetic noise site for feasibility experiments.}

The field experiment consisted of a fixed generator/load source and a sensing platform that could be moved. The source was a 39 Horsepower $40 \mathrm{~kW}$ diesel generator powering three different types of loads: a 100 meter "L" shaped string of lights suspended 1 meter above the desert floor, an inverter powering an air pump motor, and a resistive heater bank (see Figure 2). The generator was "detuned" to operate at $56.7 \mathrm{~Hz}$. As a result, the fundamental radiated frequency was $56.7 \mathrm{~Hz}$ and all higher harmonics were multiples of this fundamental. By detuning the generator, $60 \mathrm{~Hz}$ contamination problems were avoided. As will be seen, the $3.3 \mathrm{~Hz}$ frequency difference was ample for spectral peaks to be distinctly separated. 


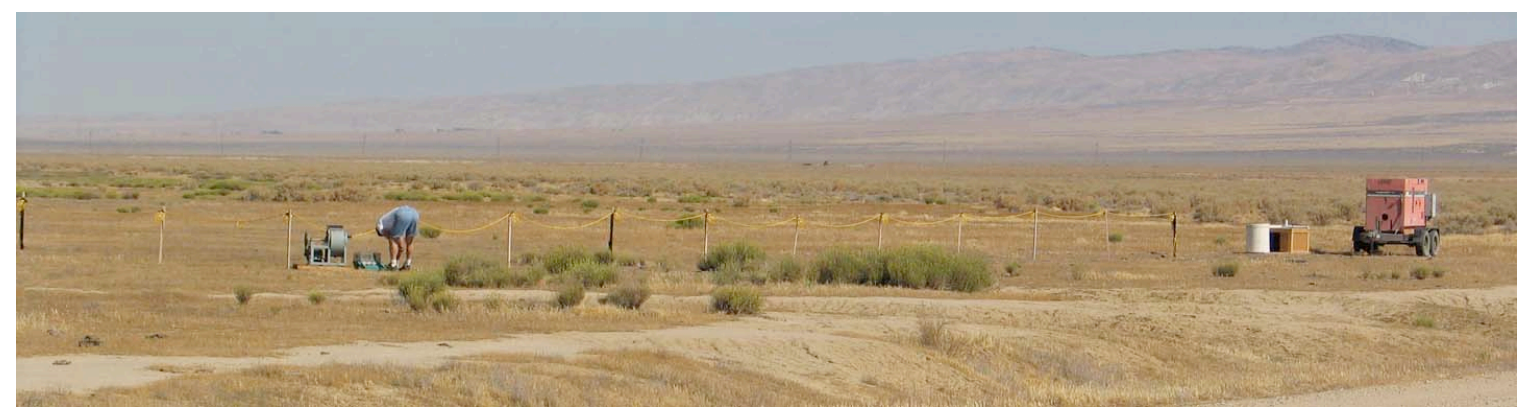

Figure 2) The generator on the right powers the three sources co-located near the individual on the left.

The field sensor platform consisted of a 3-axis E-field sensor, a 3-axis B-field sensor, and a 1-axis magnetic gradiometer. Eight data channels in all were recorded. The field sensor platform recorded time history at a sample rate of $100 \mathrm{kHz}$ with 24 bit sample resolution simultaneously time stamped. During all recording times, all electrical equipment and vehicles were shut down and acquisition platforms were battery powered. The field sensor platform is shown in Figure 3. Digitization and recording takes place in a field truck.

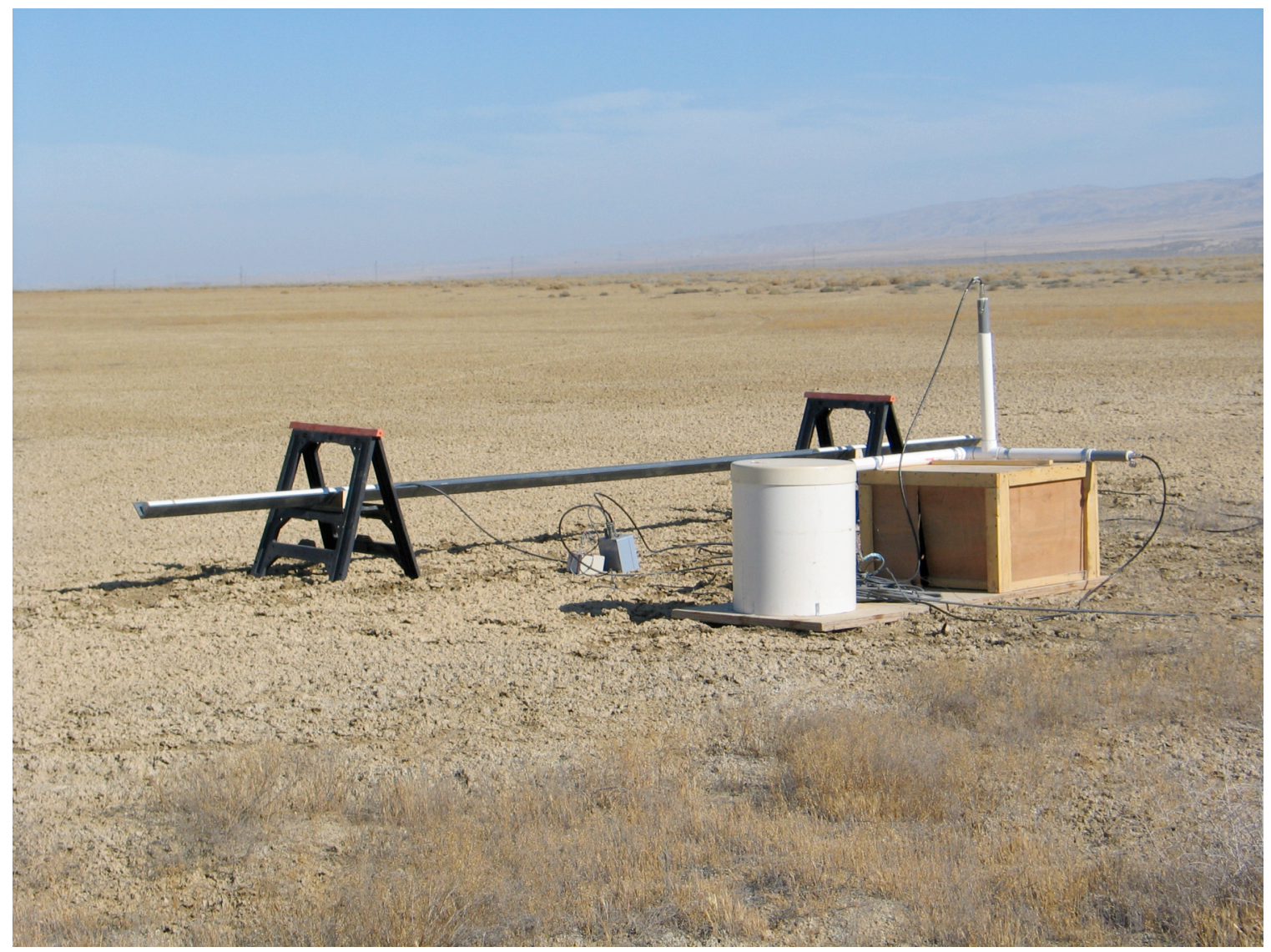

Figure 3) The sensors are 3 E-field sensors in PVC, 3 coil magnetometers on top of the wooden box, and 2 magnetometers in horizontal gradiometer configuration. 
The data collection procedure was scripted to ensure data was recorded during time periods when the generator was off, only the generator was on, and each individual load was on and was off. The scripting also insured that transient signals associated with turning the generator and loads on and off would be recorded. For all recording stations, the following script was followed for each load:

$\begin{array}{lll}\text { LIGHTS: } & \begin{array}{l}\text { Generator only on } \\ \text { Generator and lights } \\ \text { Generator only on }\end{array} & 10 \mathrm{sec} \\ & 10 \mathrm{sec} \\ \text { INVERTER: } & \begin{array}{l}\text { Generator only on } \\ \text { Inverter ramp-up }\end{array} & 10 \mathrm{sec} \\ & \begin{array}{l}\text { Gen. and inverter } \\ \text { Generator only on }\end{array} & 30 \mathrm{sec} \\ & 10 \mathrm{sec} \\ \text { HEATER } & \text { Generator off } & 10 \mathrm{sec} \\ & \text { Generator only on } & 10 \mathrm{sec} \\ & \text { Gen. and heater } & 20 \mathrm{sec} \\ & \text { Generator only on } & 10 \mathrm{sec} \\ & \text { Generator off } & 10 \mathrm{sec}\end{array}$

In all, $\mathrm{E}$ and $\mathrm{B}$ field measurements were conducted at 7 stations:

Station 1: 40 meters

Station 2: 380 meters

Station 3: 1050 meters

Station 4: 1610 meters

Station 5: 2920 meters

Station 6: 4160 meters

Station 7: 2160 meters
Opposite road side from source

South Road

North Road

North Road

North Road

Ridge

West Road

All station data was analyzed for detection at the generator operating frequency and higher harmonics. Large signal-to-noise ratio signals were measured for the fundamental and higher harmonics at the 40 meter station. There were no signals detected above a signal-to-noise ratio of one at any of the other stations. Stacking and other signal-to-noise enhancement techniques were not attempted. Analysis of the data at some stations showed large broadband background noise variations that correlated roughly with wind speed. It is possible that a signal would have been detectable at some stations if the background noise was lower at the time the measurement was taken. The analysis section of this report will focus only on the analysis results at the 40 -meter station. 


\section{ANALYSIS}

Fundamental frequency analysis at the 40-meter station was conducted to positively associate the observed spectral peak with the detuned generator and to determine if the loaded generator changed the amplitude or frequency of the spectral peak. The results are shown in Figure 4.

LTS
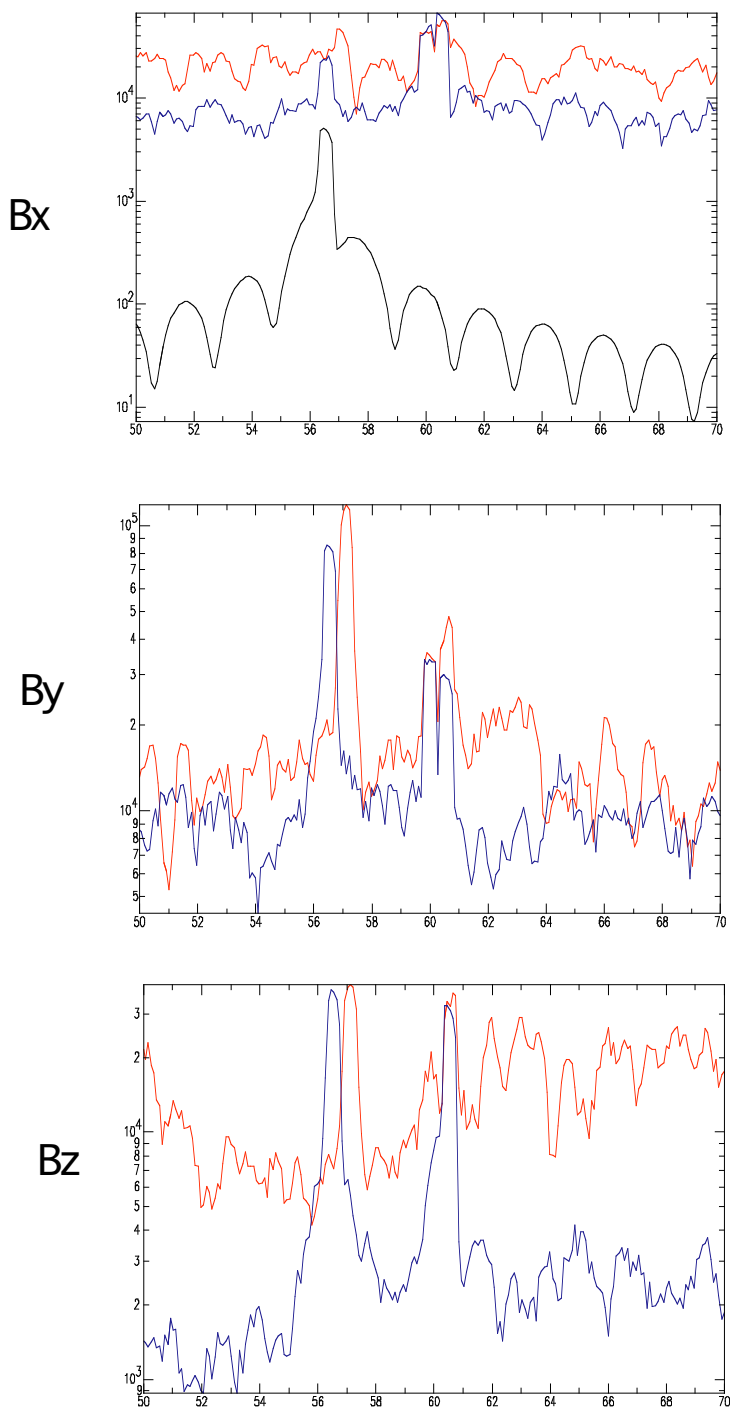

INV
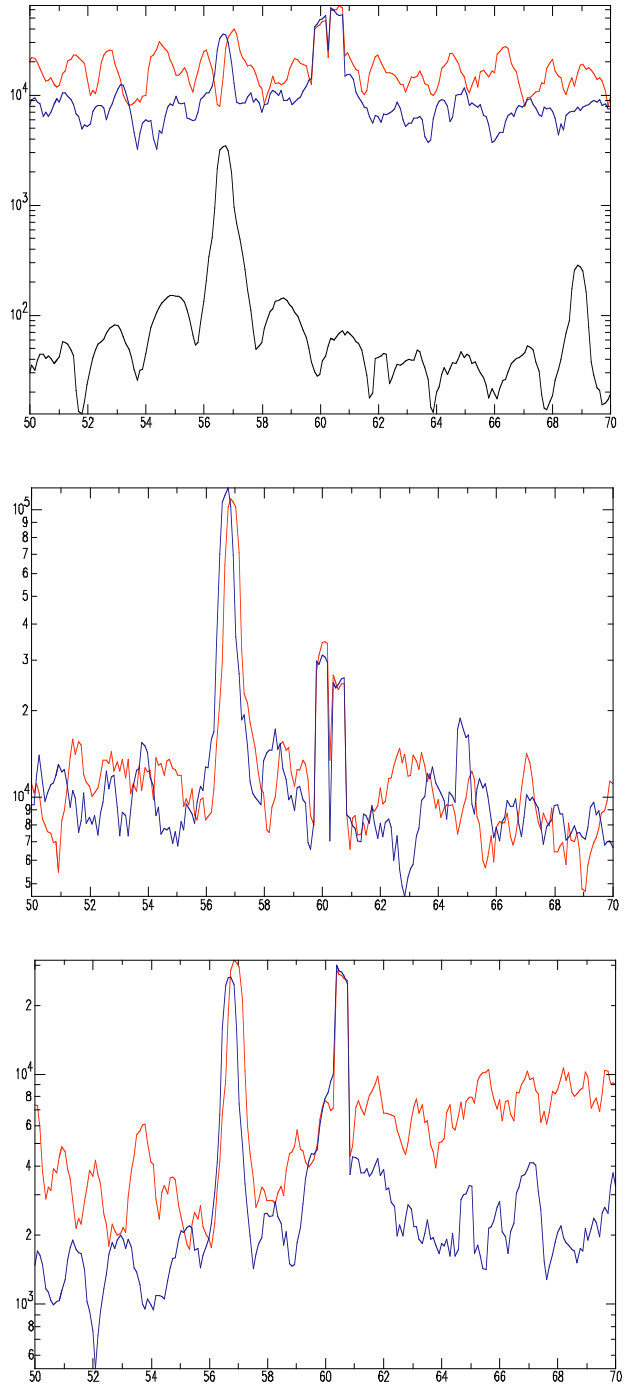

Figure 4) Spectra of the light string load (left column) and the inverter load (right column) for the components of the magnetic field indicated. Red is the generator without the load and blue is the generator with the load on. The black spectra shown on the Bx component is from a current probe on the load wire from the generator. Horizontal scale is frequency. Vertical scale is raw counts.

The spectra of the generator running without the load is in red and the spectra with the load on - lights (LTS) or inverter (INV) - is in blue. The black spectra within the top 
plots was from a current probe on the load line during the time the load was on. It serves to positively associate the radiated measured field with the driving current. From the figure it is clear that the loads do not significantly alter the amplitude of the radiated signal but they clearly shift the frequency of the generator operating frequency, in this case the shift is greater for the lights than for the inverter load. It should be noted that although the fundamental amplitude changes little with loading, the higher harmonics can change dramatically. The harmonics are particularly large when the inverter load is applied, presumably due to the switching power supply in that device.

The harmonics of the generator operation frequency could be detected at the 40 meter station for all B and E field channels and all load types. The inverter produced the largest amplitude harmonic peaks and number of harmonics (detectable to the $31^{\text {st }}$ ). Harmonics of the inverter source are shown in Figure 5.

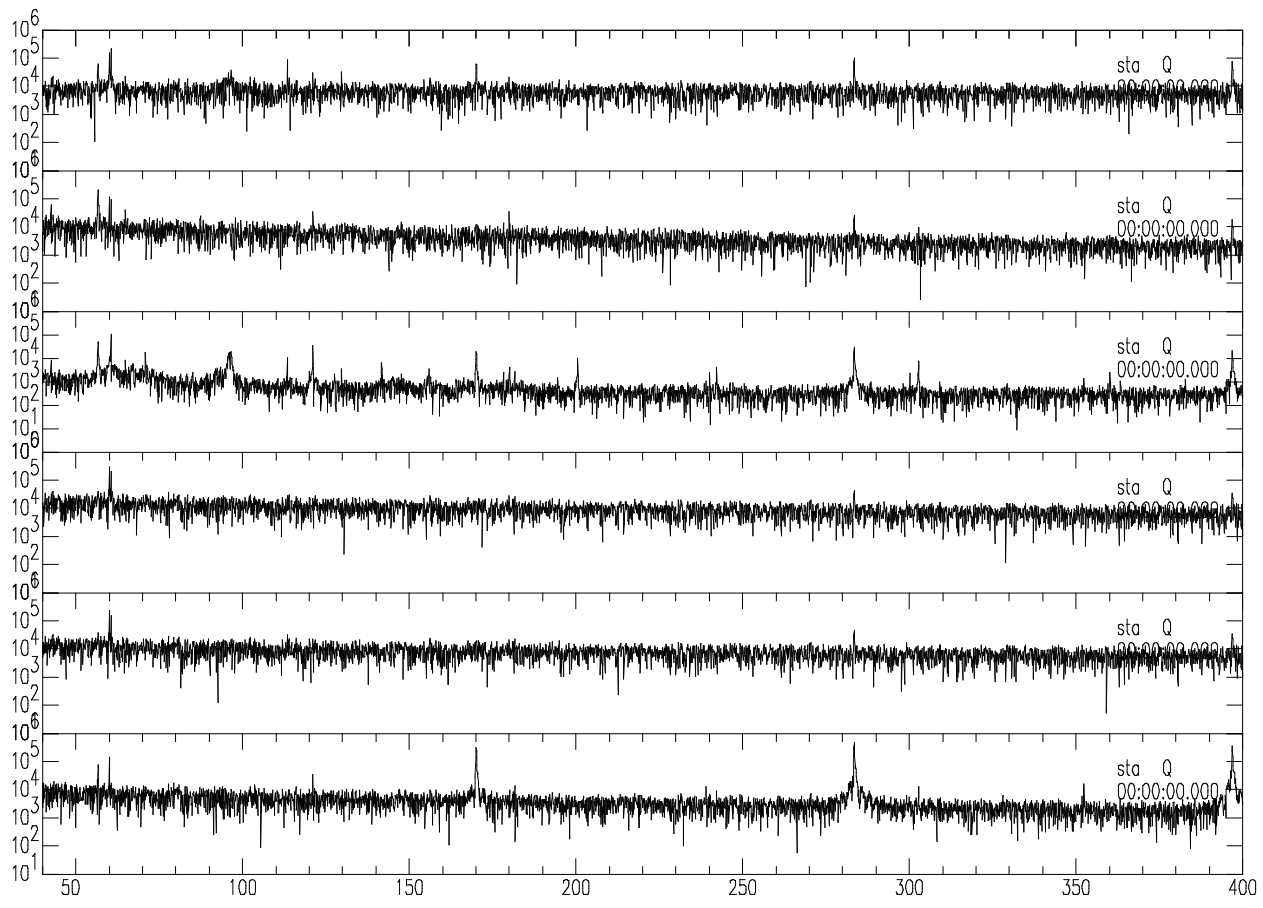

Figure 5) The spectra of the $E$ and $B$ field channels from the inverter load at the 40-meter station to $400 \mathrm{~Hz}$. The spectra, from top to bottom are: $\mathrm{Bx}, \mathrm{By}, \mathrm{Bz}, \mathrm{Ex}$, Ey, Ez.

In this figure the $56.7 \mathrm{~Hz}$ and $60 \mathrm{~Hz}$ peaks can be clearly observed and are distinctly separated. The harmonics most apparent are associated with the generator, not harmonics of background $60 \mathrm{~Hz}$. The spectra, top to bottom are Bx, By, Bz, Ex, Ey, Ez. The fundamental and higher harmonics vary greatly in signal-to-noise between $\mathrm{E}$ and $\mathrm{B}$ field components.

The back-azimuth method developed here utilizes data acquired from 3-component Eand B-field sensors and associated recording equipment. Analysis of the resulting sixcomponent broadband E- and B-field data stream provides the bearing or spatial 
location of a radiating electrical source/load system as well as the distribution of electrical harmonics emitted by the system (see Figure 6). It should be noted here that the specific analysis method employed has not been described. A record of invention on the analysis procedure for the back-azimuth calculation is being submitted at the time of this writing. Details will be provided on inquiry after the record of invention has been recorded.

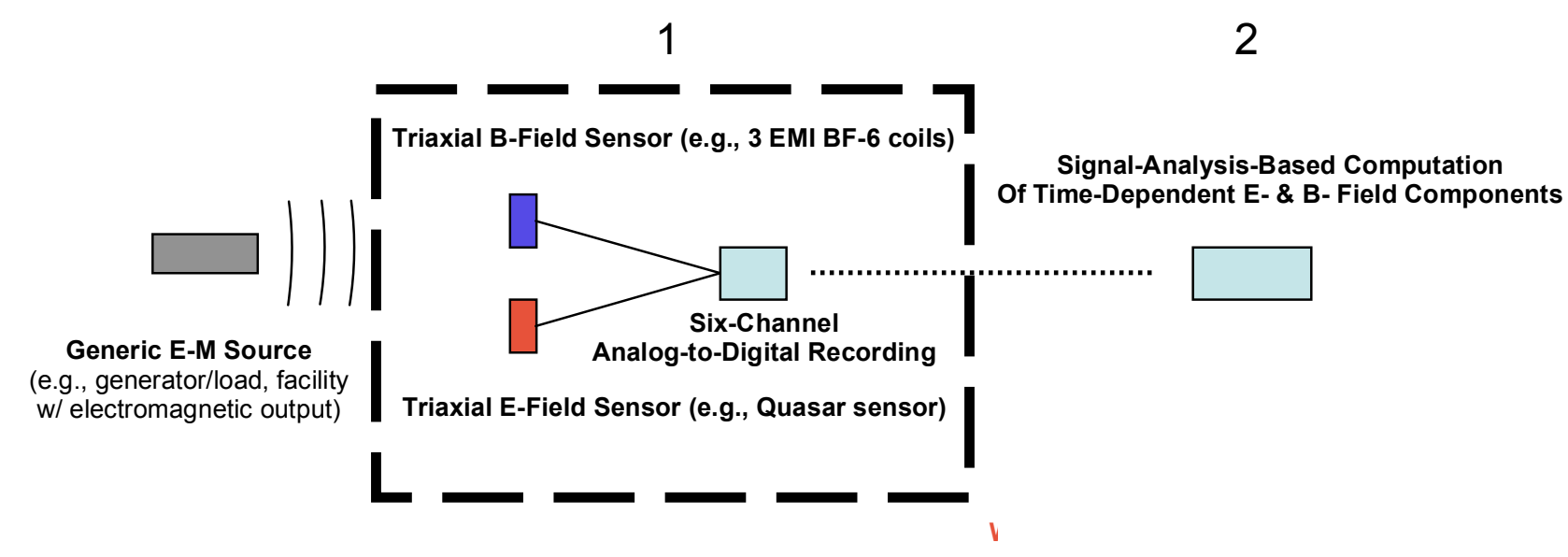

Figure 6) The basic idea of this approach is illustrated schematically above. The first stage (dashed box) results in a 6-channel $E$ and $B$ field digital data stream. The $2^{\text {nd }}$ stage computes a back-azimuth for each data point, utilizing the 6 channels ( $E$ and $B$ vectors).

The first stage involves signal sensing and conversion of the analog signal from the Eand B-field sensors to a digital format. Six channels are recorded corresponding to the three-axis measurements of both the electric and magnetic fields. The vector components of the $\mathrm{E}$ and $\mathrm{B}$ fields are necessary for determination of the back-azimuth.

The second stage involves analyzing the broadband digital data stream resulting from the first acquisition and analog-to-digital conversion stage. Two methods of analysis can be used to calculate required E- and B-field components from the signal and noise data stream.

The resulting back-azimuth vectors are binned and plotted on a rose plot that shows dominant vector directions calculated. The results for a 1-second analysis $(100,000$ data points) of the back-azimuth calculated for the 40-meter station when the inverter load is on is shown in Figure 7. The upper left plot is for the $7^{\text {th }}$ harmonic, the upper right plot is for the $9^{\text {th }}$ harmonic, the bottom left is for the $31^{\text {st }}$ harmonic (the highest detected) and the bottom right is for $60 \mathrm{~Hz}$ "noise". The consistent direction seen in the three harmonic plots shown was also seen in the fundamental and all other harmonics analyzed that were clearly detected on all $\mathrm{B}$ and $\mathrm{E}$ field channels. The direction points roughly to the distributed source. The $60 \mathrm{~Hz}$ plot shows two preferred directions and less consistency in the bearing. The preferred directions roughly point to major cities in 


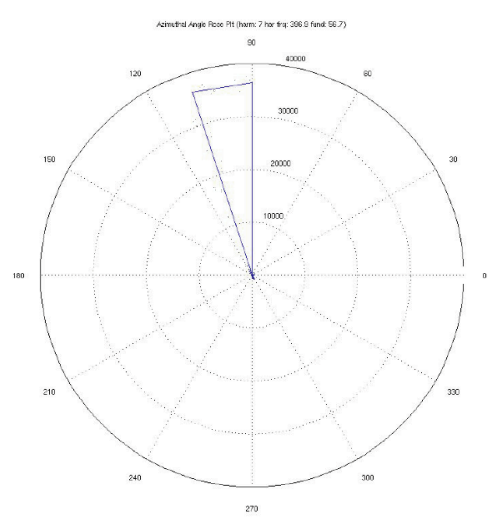

Azimuthal Angle Fose Flt (harm: 31 har frq. 1757.7 fund: 56.7)

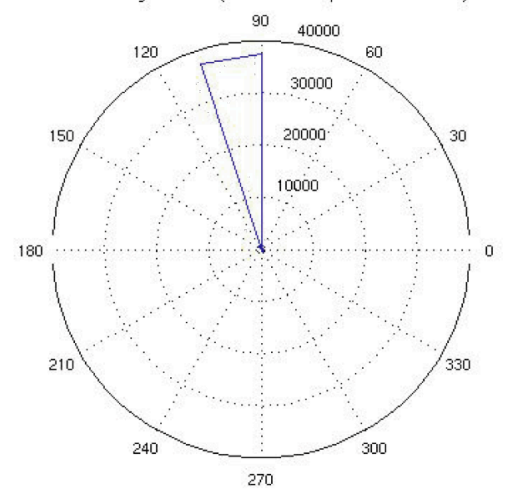

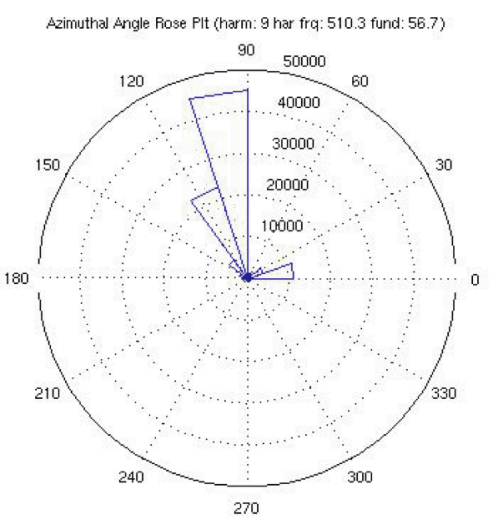

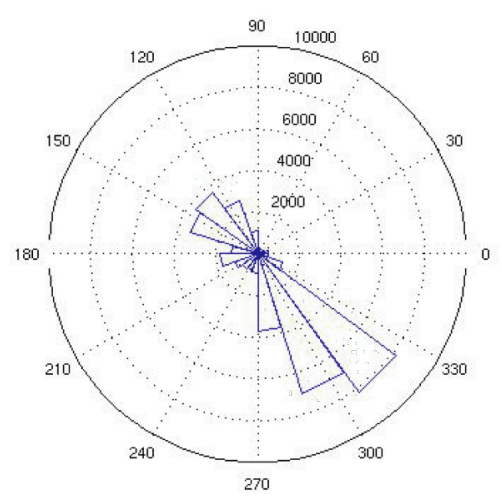

Figure 7) Binned direction plot of the calculated back-azimuths at the 40-meter station when the inverter was on. Top left is the $7^{\text {th }}$ harmonic, top right is the $9^{\text {th }}$ harmonic, bottom left is the $31^{\text {st }}$ harmonic, bottom right is $60 \mathrm{~Hz}$ background noise.

the region. This is only an observation, other studies are needed to determine if this method is positively associating directions to large sources of "background" $60 \mathrm{~Hz}$ noise. 


\section{CONCLUSIONS}

The feasibility study has enabled the collection of a broadband $(1 \mathrm{~Hz}-50 \mathrm{kHz})$ data set of isolated electromagnetic signals and background noise at a high dynamic range (24 bits). The data collection utilized a relatively new E-field sensor that allowed for full vector $\mathrm{E}$ and $\mathrm{B}$ field point measurements in the frequency band indicated. The analysis of this vast data set encompassing some 65 gigabits of information was only cursory, given the project funding and time constraints, and hence all conclusions must be considered tentative.

Although an electromagnetic field was clearly measured at the 40-meter station, no clear indication of a detectable field could be measured at stations farther away owing to high background noise levels. Stacking and other methods, such as adaptive or noise-canceling filtering, to bring a small signal out of the noise were not fully explored and could possibly expose a small signal. It has been shown that if a signal exists at the farther stations, the narrow band signal-to-noise ratio is less than one. This conclusion must be tempered by the observation that the broadband background $\mathrm{E}$ and $\mathrm{B}$ field noise was highly variable and erratic, so that at some stations during data collections the noise was $40 \mathrm{~dB}$ or higher than at other stations and times.

The analysis of the 40-meter station yielded some interesting results that need to be more fully explored. Fundamental and harmonic signals were detected for each of the source types but the inverter source showed the richest set of harmonics. When loads were added to the free-running generator, frequency shifts in the fundamental and associated harmonics could be clearly detected. Finally, a narrow-band back-azimuth analysis was conducted on the $\mathrm{E}$ and $\mathrm{B}$ field at the fundamental and higher harmonics of the detected signals, primarily using the inverter source. The back-azimuth vectors calculated point in a stable and consistent direction for all harmonics analyzed with sufficient signal-tonoise. This may be a method to determine a back-azimuth to an unknown source location. Applying the same analysis methodology to background $60 \mathrm{~Hz}$ signals produced bimodal directions that roughly correlate with the directions to major population centers from the field location. This may yield a method for analysis of the background noise field. A record of invention describing this new back-azimuth method has been submitted to the Intellectual Property Law Group. 


\section{ACKNOWLEDGEMENTS}

We are indebted to the Bureau of Land Management for granting site use permission in The Carrizo Plain National Monument. We thank Pat Lewis and Stan Martins for excellent support in the field. Craig Schultz was a strong supporter and source of optimism. Finally we thank Ken Jackson and Karl van Bibber for their keen interest and insightful comments through all phases of the project. 
This work was performed under the auspices of the U.S. Department of Energy by the University of California, Lawrence Livermore National Laboratory under Contract No. W-7405-Eng-48. 